\title{
Article \\ Study of the Rheological Properties of PVC Composites Plasticized with Butoxyethyl Adipates
}

\author{
Irina N. Vikhareva*D, Guliya K. Aminova and Aliya K. Mazitova \\ Applied and Natural Sciences Department, Ufa State Petroleum Technological University, Mendeleeva St. 195, \\ 450080 Ufa, Russia; aminovagk@inbox.ru (G.K.A.); elenaasf@yandex.ru (A.K.M.) \\ * Correspondence: irina.vikhareva2009@yandex.ru
}

check for updates

Citation: Vikhareva, I.N.; Aminova, G.K.; Mazitova, A.K. Study of the Rheological Properties of PVC Composites Plasticized with Butoxyethyl Adipates. ChemEngineering 2021, 5, 85. https://doi.org/10.3390/ chemengineering 5040085

Academic Editors: Alírio E. Rodrigues and Timothy Hunter

Received: 10 October 2021

Accepted: 6 December 2021

Published: 13 December 2021

Publisher's Note: MDPI stays neutral with regard to jurisdictional claims in published maps and institutional affiliations.

Copyright: (c) 2021 by the authors. Licensee MDPI, Basel, Switzerland. This article is an open access article distributed under the terms and conditions of the Creative Commons Attribution (CC BY) license (https:// creativecommons.org/licenses/by/ $4.0 /)$.

\begin{abstract}
Polyvinyl chloride compositions are widely used to obtain various types of products. In the composition of the PVC composite, one of the main ingredients is a plasticizer, the introduction of which makes it possible to vary the characteristics of the obtained polymeric materials and products and significantly expand the range of their application. Manufacturability in the processing of polyvinyl chloride compositions serves as an important criterion for the suitability and economic efficiency of the developed plasticizer. In the modern world, the high quality of products is directly related to their environmental safety. In this regard, the work describes the production of environmentally friendly plasticizers based on adipic acid and ethoxylated butanol. Their physicochemical indicators have been investigated. The effect of the obtained additives on the rheology of PVC composites has been studied. The values of the flow characteristics of the melts of the developed PVC compositions plasticized with butyl butoxyethyl adipate and decyl butoxyethyl adipate were estimated. It was shown that the fluidity of melts, in comparison with compounds of a similar composition containing industrial dioctyl phthalate, is characterized by even slightly higher values.
\end{abstract}

Keywords: adipate plasticizer; esterification; melt flow index; polyvinyl chloride; rheology

\section{Introduction}

Polyvinyl chloride is widely used in many industries, such as medicine, transport, construction, packaging, and toys [1-3]. However, PVC is not used in its pure form, since the polymer is a brittle and unstable material. One of the main problems encountered when working with PVC is the low stability of its macromolecules [4]. During operation, the polymer is exposed to chemical, biological, and physical factors, which leads to a significant irreversible change in its physical and chemical properties, that is, to aging [5-7]. In this regard, in the manufacture of materials and products from PVC, various chemical additives are used to ensure the required performance properties.

The main role of auxiliary substances is to facilitate the processing of polymer mixtures and impart the necessary properties to finished products [8]. Using additives, a wide range of physical properties of plastic compounds is obtained, which makes it possible to produce a wide variety of products: from very soft, gel-like to elastic, rigid materials [9].

Most of the PVC composition is occupied by plasticizers, which impart softness and flexibility to polymers [10]. Plasticized PVC compositions are processed at high temperatures, usually well above the decomposition temperature of PVC.

Plasticizers are organic compounds used to modify the properties of polymers, to give them elasticity, frost resistance, and to reduce the processing temperature [11,12]. The introduction of these compounds into the PVC formulation makes it possible to obtain materials and products with a given elasticity that remains in a wide temperature range, with a high elongation at break. Plasticizers must be compatible with the polymer, have low volatility, and have high chemical resistance. In addition, plasticizers (depending on the areas of application) should be colorless, odorless, and non-toxic, and resistant 
to extraction with water, oils, detergents, as well as to the action of radiation, light, and fire $[13,14]$.

About $90 \%$ of the manufactured plasticizers belong to the group of ester plasticizers [15]. The dominant part of this group is made up of phthalic acid esters: phthalates occupy about $80 \%$ of the market. Other esters are used in industry in much smaller volumes [16].

However, polyvinyl chloride composites with the use of phthalate plasticizers have a low rate of biodegradation [17-20]. The most promising area of research in this area is the development of phthalate-free plasticizers and the production of PVC materials based on them, which have good performance and a high rate of biodegradation in the environment [21-24].

One of the modern approaches to the creation of materials destructible in natural conditions is based on the use of biodegradable additives that undergo decomposition by soil microorganisms, which contributes to loosening the structure, reducing the resistance of the filled polymer materials, and, as a result, mechanical destruction of the product.

Analysis of the information showed that in order to obtain materials with standard reproducible physical and mechanical characteristics and satisfactory operational properties, adipate plasticizers can be used, which are significantly superior to phthalates in their ability to biodegrade by bacteria and are environmentally safe compounds.

Adipate plasticizers are flexible at low temperatures, have excellent electrical conduction, excellent weather resistance, and good heat resistance [8]. Adipates are used to make transparencies for food packaging. Low molecular weight esters are used as high temperature raw materials for the production of biodegradable solvents with low toxicity. The industrial plasticizer dioctyl adipate has excellent performance at high and low temperatures and is used as an intermediate for a wide range of chemical compounds. In addition, DOA is included in the list of safe substances permitted for use in contact with food $[25,26]$.

The manufacturability of plasticizers in the processing of PVC compositions is assessed by the rheology of the melts. A fairly reliable and widespread method in practice is to determine the processability of polymers by the value of the melt flow rate (MFR). This indicator allows you to establish the temperature range of processing of the polymer composition and provide the necessary conditions for its implementation [27-31].

For this reason, to expand the range of environmentally friendly plasticizers based on adipic acid, as well as to obtain PVC composites capable of biodegradation under environmental conditions, we obtained butoxyethyl adipinates, studied their properties important for practical use as plasticizers of polyvinyl chloride, and also studied rheology of PVC composites based on them.

\section{Materials and Methods}

\subsection{Materials}

Adipic acid (purum 99.8\%) was bought from Radici Group (Selbitz-Hochfranken, Germany, Bavaria). Butyl alcohol (purum 99.7\%), and decyl alcohol (purum 99\%) were bought from The «Rearus» (Moscow, Russia). Ethylene oxide $(98.2 \%)$ is a white solid that was bought from ECOTECH CCP (Moscow, Russia). Sodium hydroxide (98.2\%) was purchased from JSC "Caustic" (Sterlitamak, Russia); it is a white solid. P-Toluenesulfonic acid (95\%) was purchased from Component-Reagent (Moscow, Russia); it is a white solid. Toluene was purchased from PJSC "Joint-Stock Oil Company Bashneft" (Ufa, Russia). It is a colorless liquid with a characteristic smell, with a main substance content of $99.5 \%$. For polyvinyl chloride (JSC "Caustic", Sterlitamak, Russia), we used industrial samples of suspension polyvinyl chloride PVC 7059M with a bulk density from 0.45 to $0.55 \mathrm{~g} / \mathrm{cm}^{3}$, with a $\mathrm{K}$ value from 70 to 73 , with a residue after sieving on a sieve with a mesh $\mathrm{N} 0063-5 \%$, for the manufacture of plasticized products. 


\subsection{Synthesis Methods}

\subsubsection{Synthesis of Ethoxylated Butanol}

The synthesis of butoxyethanol was described earlier [32,33]. Briefly, the estimated amount of epy corresponding alcohol and sodium hydroxide is loaded into the chemical reactor, and heated to $110-120^{\circ} \mathrm{C}$. The flask with the contents is blown with nitrogen, the prepared ethylene oxide is slowly introduced. The temperature in the flask is maintained for an additional $1 \mathrm{~h}$, and then the contents are cooled. Sodium hydroxide is neutralized, the reaction mass is filtered, the fraction boiling to $50^{\circ} \mathrm{C}$ at $10 \mathrm{~mm} \mathrm{Hg}$ is distilled off from the reaction mixture.

Butoxyethanol is a colorless oily liquid soluble in water. The yield was $106.8 \mathrm{~g}(90.5 \%$ of theoretical).

\subsubsection{The Synthesis of Esters of Adipic Acid and Ethoxylated Butanol}

All adipate esters were synthesized according to the earlier method described in [34]. For this, $1 \mathrm{~mol}$ of ethoxylated alcohol, $150 \mathrm{~mL}$ of toluene, $3.0 \mathrm{~g}$ ( $1 \%$ by weight) of the catalyst and $1 \mathrm{~mol}$ of adipic acid were loaded into the flask. Stirring was included. The reaction mixture was heated to $90-95^{\circ} \mathrm{C}$ for $1.5 \mathrm{~h}$. After reaching the required acid and ester number of the esterificate, the corresponding alkanol was added to the reactor $(1.2 \mathrm{~mol})$. Heating continued for $2-3 \mathrm{~h}$. The reaction flask was cooled. The target ester was allocated. All obtained adipates are the light clear liquids.

The yield of butyl butoxyethyl adipate was $265.8 \mathrm{~g}$ ( $88.0 \%$ of theoretical).

The yield of decyl butoxyethyl adipate was $341.2 \mathrm{~g}$ ( $88.4 \%$ of theoretical).

\subsection{Characterization}

\subsubsection{Analysis of the Physico-Chemical Characteristics of Adipates}

The determination of the physico-chemical characteristics of the synthesized esters was carried out according to regulatory standards (acid number, ester number, density) [35].

Determination of plasticizer density was carried out according to regulatory standards for plasticizers [36].

\subsubsection{Characterization of Adipates}

For the synthesized adipates, IR spectra were obtained by FTIR spectroscopy (KBr tablets). The FTIR-8400S FTIR spectrometer (Shimadzu Corporation, Japan, Shimadzu) was used for characterization. The range is $450-3700 \mathrm{~cm}^{-1}$ at room temperature. Resolution$4 \mathrm{~cm}^{-1}$, number of scans-20.

\subsubsection{High Performance Liquid Chromatography}

The products obtained were confirmed by HPLC (LC-10 from SHIMADZU, Kyoto, Japan) in a reversed phase mode. Separation of the components of the resulting mixture with a volume of $10 \mu \mathrm{L}$ was carried out on a column $(150 \mathrm{~mm} \times 4.6 \mathrm{~mm})$. Separon-C18 with a particle size of $5 \mu \mathrm{m}$ was used as a sorbent; eluent: Acetonitrile-water mixture in a volume ratio of $67 / 33$. The flow rate of the eluent is $0.5 \mathrm{~mL} / \mathrm{min}$. A model refractometric detector (RIDK 101, Prague, Czech Republic) was used for detection. Quantitative analysis was carried out using the absolute calibration method. Adipic acid, alcohols and esters were used for calibration.

\subsubsection{TGA of Esters}

For the study the thermal stability of plasticizers, a TGA/DSC-1 thermal analysis device (Mettler Toledo, Greifensee, Switzerland) was used.

Thermal analysis of the samples were carried out in a dynamic mode at a constant heating rate of $5 \mathrm{~K} / \mathrm{min}$ in the temperature range from 25 to $500^{\circ} \mathrm{C}$ in air. The analyzed sample in the amount of $5-10 \mathrm{mg}$ was placed in crucible $(100 \mu \mathrm{L})$ of aluminum oxide. The results were processed using a computer. 


\subsubsection{DSC Analysis of Esters}

The melting and crystallization points of plasticizers were determined by differential scanning calorimetry on a DSC-1 instrument (Mettler Toledo, Greifensee, Switzerland).

The analysis was carried out in dynamic mode with a constant heating/cooling rate of the sample $-10 \mathrm{~K} / \mathrm{min}$ in the temperature range from -50 to $150{ }^{\circ} \mathrm{C}$ in air. The analyzed sample in the amount of $4-8 \mathrm{mg}$ was placed in crucible $(40 \mu \mathrm{L})$ and sealed with a lid using a press. The results were processed using a computer.

\subsubsection{Determination of the Melt Flow Rate of Polymer Composition}

The melt flow rate (MFR) was estimated by capillary viscometry on an IIRT-AM plastometer [37]. The MFR value corresponds to the mass of polymer in grams flowing out of the capillary (capillary $8 \mathrm{~mm}$ long, $2.09 \mathrm{~mm}$ in diameter) of the device in $10 \mathrm{~min}$ at a certain temperature and pressure. The MFR of PVC composites was measured in the temperature range $170-200^{\circ} \mathrm{C}$ at a load of $49 \mathrm{~N}$. 4-5 g of the studied PVC composition was introduced into the device heated to a predetermined temperature, kept under pressure for $5 \mathrm{~min}$, then the capillary was opened, causing the melt to flow out compositions.

To measure the MFR parameter, at least five extruded segments of the composite were used, cut off at certain equal time intervals. The mass of the obtained extruded segments with an error of not more than $0.0001 \mathrm{~g}$ was measured after they were cooled. The value of the $M F R$ parameter ( $\mathrm{g} / 10 \mathrm{~min}$ ) was calculated by Equation (1):

$$
M F R=\frac{m * 600}{t}
$$

where $m$-average mass of extruded segments, $\mathrm{g}$; $t$ - time interval between two consecutive cutoffs of segments, $\mathrm{s}$.

\subsection{Preparation of Film Samples}

All composition ingredients were mixed in a two-stage laboratory mixer for $60 \mathrm{~min}$. Film samples were obtained by rolling on laboratory rollers at a temperature of $165-175{ }^{\circ} \mathrm{C}$ for $5 \mathrm{~min}$.

\section{Results and Discussion}

\subsection{Synthesis of Butoxyethanol}

The preparation of butoxyethanol is described in detail in the works [32-34]. The characteristics of the product obtained are given in the same place [32-34].

Butoxyethanol with a degree of oxyethylation $n=1$ : density -0.9648 , refractive index1.4267 , molecular weight (calculated) -118 , yield $-90.5 \%$, reaction time $-0.5 \mathrm{~h}$.

\subsection{The Synthesis of Esters of Adipic Acid and Butoxyethanol}

The adipates of ethoxylated butanol were obtained by a two-stage esterification of a dicarboxylic acid (Scheme 1). Initially, the corresponding alcohol and solvent were loaded into the chemical reactor, then adipic acid was added in the ratio acid: alcohol $=1: 1$. Toluene was used as a solvent to remove the water released during the synthesis; an inert gas was also bubbled through the reaction mass. Later, a higher molecular weight alcohol was loaded into the reactor in the ratio acid: alcohol $=1: 1.2$. Isolation of adipates was carried out according to the standard method [34]. The output of target products is at least $80 \%$.

The physicochemical parameters of the synthesized adipates are shown in Table 1.

\subsection{High Performance Liquid Chromatography}

The obtained chromatograms in both cases clearly showed peaks of the synthesized esters of butyl butoxyethyl adipate and decyl butoxyethyl adipate. The purity of the reaction products obtained is in accordance with usual standards. 


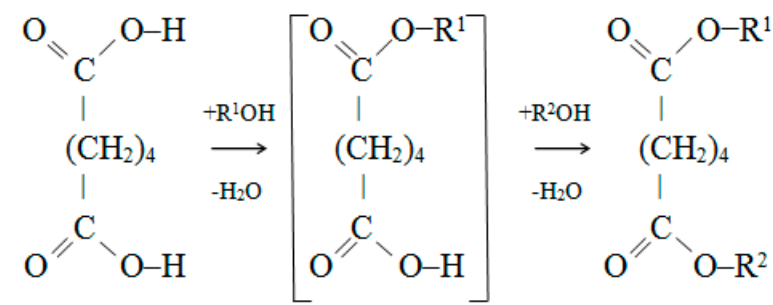

where $\mathrm{R}^{1}=\left[\mathrm{CH}_{2}-\mathrm{CH}_{2}-\mathrm{O}\right]-\mathrm{C}_{4} \mathrm{H}_{9}, \mathrm{R}^{2}=$ butyl, decyl

Scheme 1. Synthesis of esters of adipic acid.

Table 1. Physicochemical parametres of alkyl butoxyethyl adipates.

\begin{tabular}{ccccc}
\hline & \multicolumn{4}{c}{ Indicators } \\
\cline { 2 - 5 } Ester & $\begin{array}{c}\text { Molecular } \\
\text { Weight }\end{array}$ & $\begin{array}{c}\text { Acid Number, } \\
\mathbf{~ m g ~ K O H / g}\end{array}$ & $\begin{array}{c}\text { Ester Number, } \\
\mathbf{~ m g ~ K O H / g ~}\end{array}$ & $\mathbf{d}^{\mathbf{2 0}} \mathbf{4}^{\circ}$ \\
\hline $\begin{array}{c}\text { Butyl butoxyethyl } \\
\text { adipate (BBEA) (I) }\end{array}$ & 302 & 0.1 & 369 & 1.0452 \\
\hline $\begin{array}{c}\text { Decyl butoxyethyl } \\
\text { adipate (DBEA) (II) }\end{array}$ & 386 & 0.1 & 288 & 1.1003 \\
\hline
\end{tabular}

\subsection{IR Spectra}

Spectra of the obtained esters default an absorption band in the region of $1685-1687 \mathrm{~cm}^{-1}$, corresponding to stretching vibrations of the carbonyl group in associates of aliphatic carboxylic acids (Figures 1 and 2). Thus, a strong characteristic band corresponding to the ester bands is present in the $1737 \mathrm{~cm}^{-1}$ region. There are also absorption bands that refer to the vibrations of the $\mathrm{C}-\mathrm{O}-\mathrm{C}$ ester fragment: $1176 \mathrm{~cm}^{-1}$ for butyl butoxyethyl adipate, $1173 \mathrm{~cm}^{-1}$ for decyl butoxyethyl adipate.

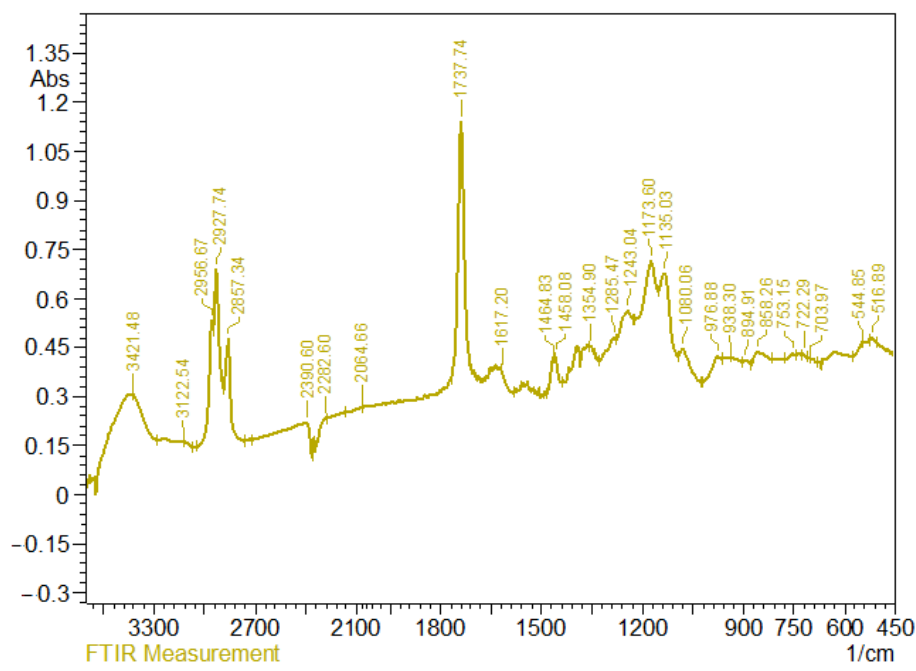

Figure 1. FTIR spectra of butyl butoxyethyl adipate.

\subsection{TGA of Esters of Adipic Acid}

A sample of industrial plasticizer di-2-ethyl hexyl phthalate (DOP) was used as a comparison.

It follows from the results of thermal analysis that decyl butoxyethyl adipate is characterized by a higher thermal stability compared to DOP: the temperatures corresponding to the beginning of the decrease in the sample weight upon heating are 153 and $132{ }^{\circ} \mathrm{C}$, respectively. The temperature value corresponding to the maximum decomposition of 
the product is at a level similar to that for DOP: $278{ }^{\circ} \mathrm{C}$ and $285^{\circ} \mathrm{C}$, respectively. The temperatures corresponding to the complete decomposition of the product are $498^{\circ} \mathrm{C}$ and $467^{\circ} \mathrm{C}$ for DOP.

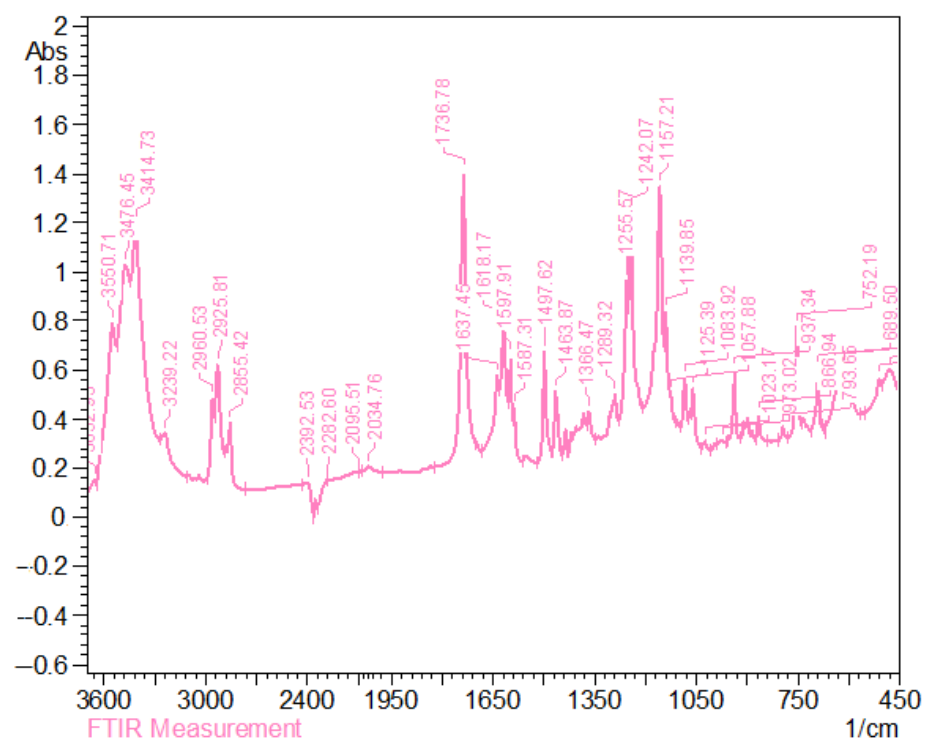

Figure 2. FTIR spectra of decyl butoxyethyl adipate.

Thermal analysis of the butyl butoxyethyl adipate sample (I) showed that the main listed characteristics, according to the given thermogram, are slightly inferior to DOP (Figures 3-5).

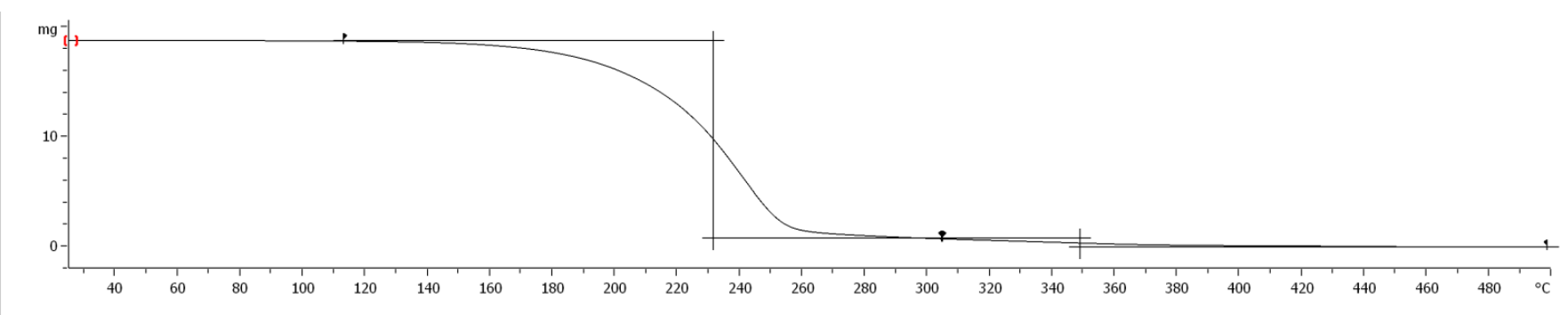

Lab: METTLER

Figure 3. TGA curve of butyl butoxyethyl adipate.

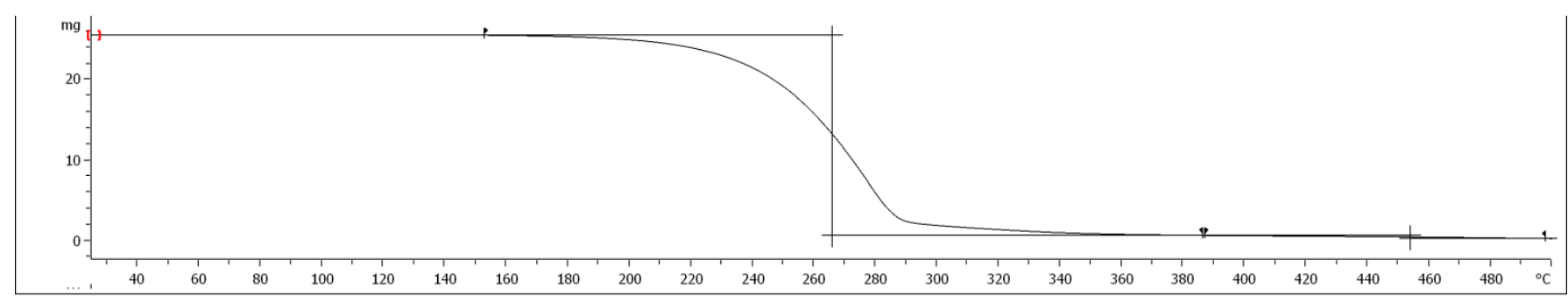

Lab: METTLER

Figure 4. TGA curve of decyl butoxyethyl adipate. 


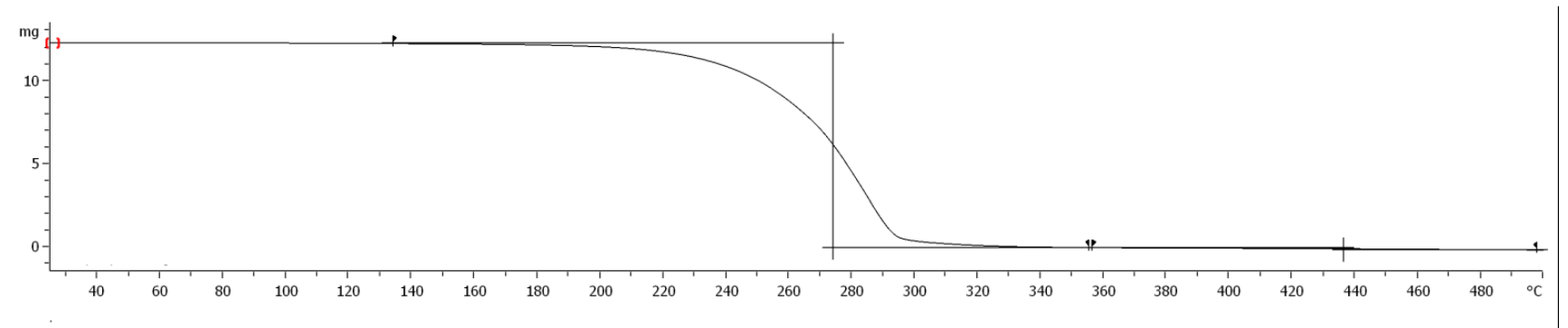

Lab: METTLER

Figure 5. TGA curve of DOP.

On the DSC thermograms obtained during thermal analysis, the decomposition of butyl butoxyethyl adipinate (I), decyl butoxyethyl adipinate (II), as well as the decomposition of DOP, corresponds to the characteristic exothermic effect observed at temperatures above $210^{\circ} \mathrm{C}$ and caused by the occurrence of thermooxidative degradation of the product.

DSC curves of the synthesized compounds show that during the processing of these additives in the composition of PVC compositions, weight loss due to volatility is excluded, which ensures the stability of the composition of the PVC composition during processing and, thereby, improves the manufacturability of compounds based on new plasticizers (Figures 6-8).

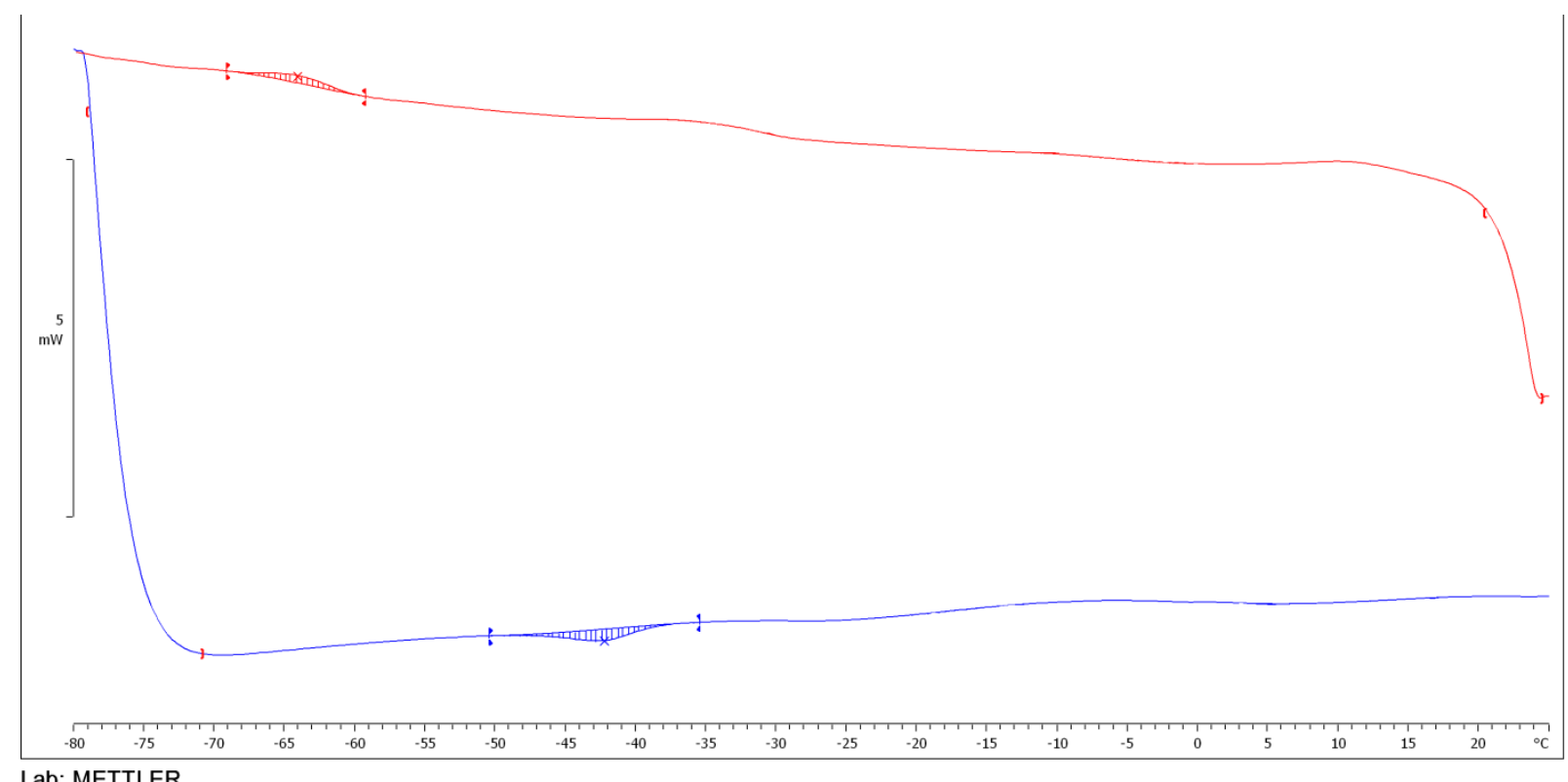

Figure 6. DSC curve of butyl butoxyethyl adipate.

\subsection{Determination of the Melt Flow Rate}

To assess the rheological properties of plasticized PVC composites, we used such a parameter as the melt flow rate (MFR) of the polymer, which is widely used in practice to characterize the processability of polymer materials and select a processing method. The studies were carried out on an IIRT-AM device in the temperature range from 160 to $205^{\circ} \mathrm{C}$.

Initially, to study the effect of the synthesized esters on the fluidity of PVC composites melts, the rheological properties of compositions containing mixtures of the DOP plasticizer with the developed adipates were studied. When preparing the PVC composition, the ratio of DOP: adipate 5:1 (mass) was used. 


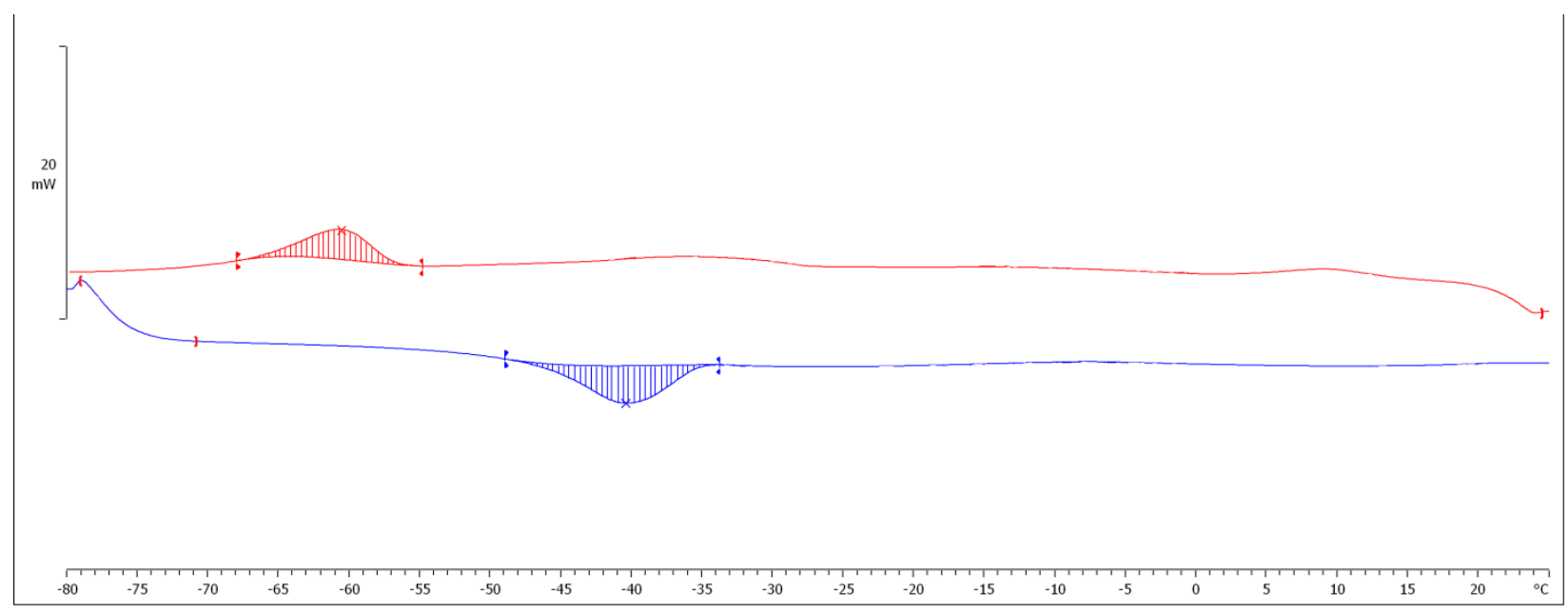

Lab: METTLER

Figure 7. DSC curve of decyl butoxyethyl adipate.

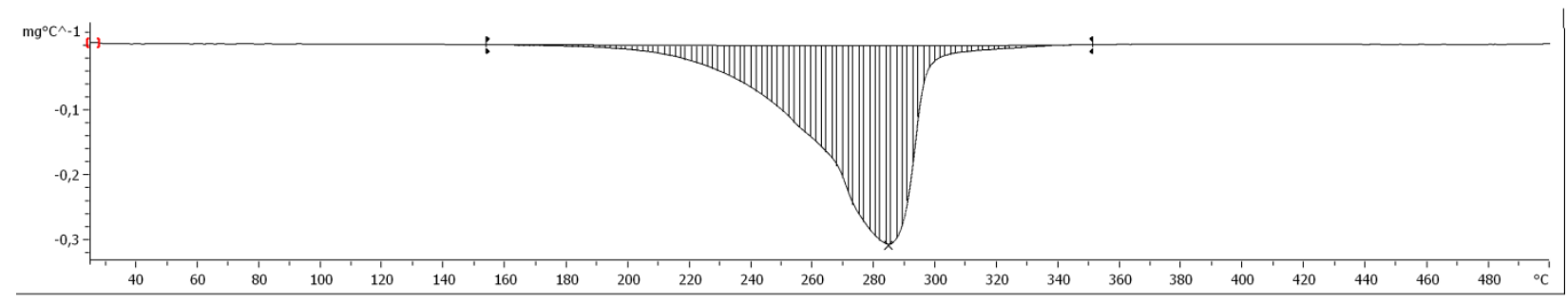

Lab: METTLER

Figure 8. DSC curve of DOP.

The temperature dependences of the MFR of the PVC composition were studied for the developed compositions of the following composition (ppm): PVC-100; plasticizer50; tribasic lead sulfate-1. The composition of the plasticizer, ppm: DOF-83.3; adipate plasticizer-16.7. The used load is $49 \mathrm{~N}$ (Figure 9).

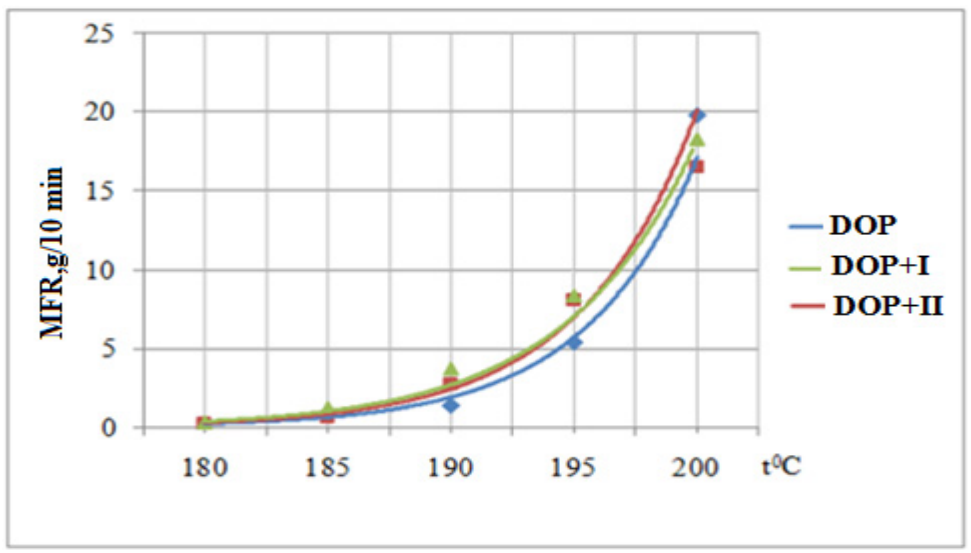

Figure 9. Dependence of the MFR of PVC composition on temperature. I-II-Symbols of plasticizers (Table 1).

Table 2 shows the color of the granules of the compiled polyvinyl chloride composition at the exit from the IIRT-AM device. 
Table 2. Test results.

\begin{tabular}{cccccc}
\hline \multirow{2}{*}{$\begin{array}{c}\text { Plasticizer } \\
\text { Composition }\end{array}$} & $\mathbf{1 8 0}{ }^{\circ} \mathbf{C}$ & $\mathbf{1 8 5}{ }^{\circ} \mathbf{C}$ & $\mathbf{1 9 0}{ }^{\circ} \mathbf{C}$ & $\mathbf{1 9 5}{ }^{\circ} \mathbf{C}$ & $\mathbf{2 0 0}{ }^{\circ} \mathbf{C}$ \\
\cline { 2 - 6 } & Yellow & Red & Red & Red & Red \\
\hline DOP & White & White & Yellow & Yellow & Yellow-Red \\
\hline DOP + I & White & White & White & Yellow & Red \\
\hline DOP + II & & & & &
\end{tabular}

It has been experimentally established that, with an increase in temperature, the melt flow rate of PVC composites increases, and this dependence is close to exponential. The use of mixtures of DOP with adipates in the composition of PVC compositions in the indicated ratios does not lead to a decrease in the fluidity of the polymer melt as compared to compounds of a similar composition containing only DOP (Figure 9).

Further, the properties of PVC compositions with the developed plasticizers of the following composition (ppm) were studied: PVC-100; plasticizer-39; tribasic lead sulfate-1. The composition of the plasticizer, ppm: DOP-83.3; adipate plasticizer-16.7. Used load-49 N (Figure 10).

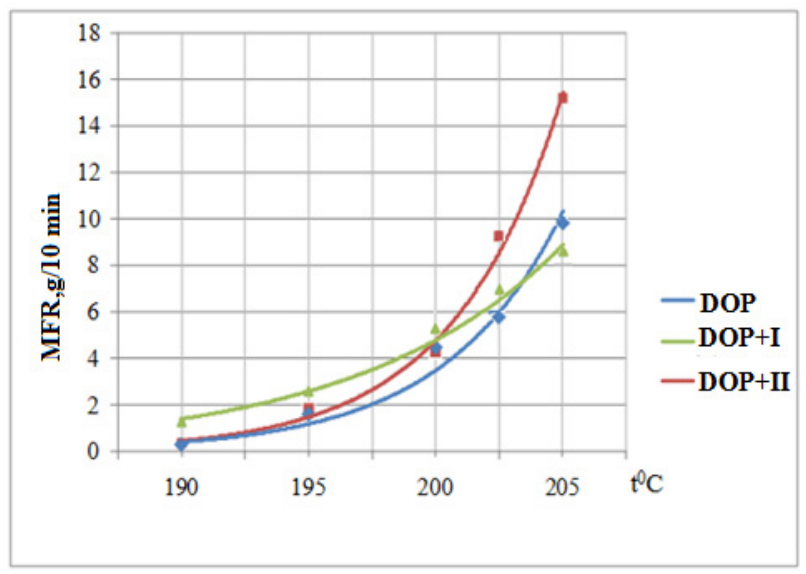

Figure 10. Dependence of the MFR of PVC composition on temperature. I-II-Symbols of plasticizers (Table 1).

Table 3 shows the color of the granules of the polyvinyl chloride composition at the exit from the IIRT-AM device.

Table 3. Test results.

\begin{tabular}{cccccc}
\hline \multirow{2}{*}{$\begin{array}{c}\text { Plasticizer } \\
\text { Composition }\end{array}$} & $\mathbf{1 9 0}{ }^{\circ} \mathbf{C}$ & $\mathbf{1 9 5}{ }^{\circ} \mathbf{C}$ & $\mathbf{2 0 0}{ }^{\circ} \mathbf{C}$ & $\mathbf{2 0 2 . 5}{ }^{\circ} \mathbf{C}$ & $\mathbf{2 0 5}{ }^{\circ} \mathbf{C}$ \\
\cline { 2 - 5 } & Yellow & Red & Red & Red & Red \\
\hline DOP & Yellow & Yellow & Yellow & Yellow & Yellow \\
\hline DOP + I & Yellow & Yellow & Yellow-Red & Red & Red \\
\hline DOP + II & & & & &
\end{tabular}

At a high concentration of the adipate plasticizer in the polymer (1:1 wt.), there are practically no differences between DOP and mixtures of DOP with the indicated esters. At a lower content of adipate plasticizer in the polymer (39 ppm), compositions based on their mixtures with DOP exhibit somewhat higher fluidity (Figure 10).

It is important to note that, when using the developed plasticizers butyl butoxyethyl adipate and decyl butoxyethyl adipate, the color of the granules obtained by extrusion from the capillary of the device acquires a noticeable bright red coloration of polymer fragments at significantly higher heating in comparison with compositions based only on 
dioctyl phthalate (Tables 2 and 3), which is probably due to the higher thermal stability of PVC compositions containing adipate plasticizers.

Since when using mixtures of DOP with the obtained compounds, even a slight increase in the MFR values of polyvinyl chloride compounds is observed, at the next stage, the rheological parameters of PVC compositions containing only butyl butoxyethyl adipate (I) and decyl butoxyethyl adipate (II) products were studied as plasticizers.

For this purpose, PVC compositions of the following composition were compiled, including (ppm): PVC - 100; adipate plasticizer-50; tribasic lead sulfate-1 (load 49 N).

The study showed that with the content of the adipate plasticizer in the amount of $50 \mathrm{ppm}$, they are characterized by even slightly higher MFR values compared to DOP (Figure 11). Moreover, compounds based on the plasticizer butyl butoxyethyl adipate exhibit higher fluidity.

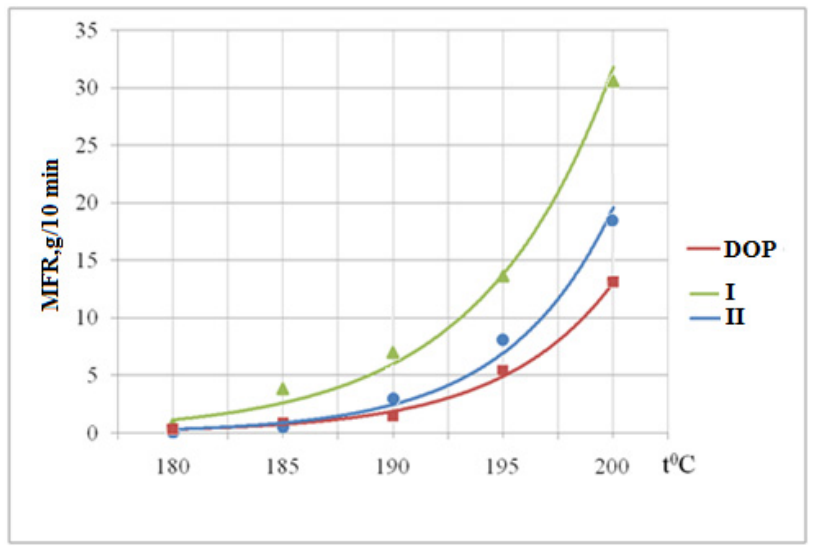

Figure 11. Dependence of the MFR of PVC composition on temperature. I-II-Symbols of plasticizers (Table 1).

Table 4 shows the color of the granules of the compiled polyvinyl chloride composition at the exit from the IIRT-AM device.

Table 4. Test results.

\begin{tabular}{cccccc}
\hline \multirow{2}{*}{$\begin{array}{c}\text { Plasticizer } \\
\text { Composition }\end{array}$} & $\mathbf{1 8 0}{ }^{\circ} \mathbf{C}$ & $\mathbf{1 8 5}{ }^{\circ} \mathbf{C}$ & $\mathbf{1 9 0}{ }^{\circ} \mathbf{C}$ & $\mathbf{1 9 5}{ }^{\circ} \mathbf{C}$ & $\mathbf{2 0 0}{ }^{\circ} \mathbf{C}$ \\
\cline { 2 - 5 } & Yellow & Red & Red & Red & Red \\
\hline DOP & Yellow & Yellow & Yellow & Yellow & Yellow-Red \\
\hline DOP + I & Yellow & Yellow & Yellow & Yellow-Red & Yellow-Red \\
\hline DOP + II & & & &
\end{tabular}

Based on the data obtained (Tables 2-4), we can conclude that the thermal stability provided by the developed plasticizers during processing is slightly higher than similar compounds with DOP content, which confirms the change in the color of the plasticates at the exit from the IIRT-AM device.

For the possibility of using the developed compounds as PVC plasticizers in composites for various purposes, the values of the flow rate of the melts of the following composition were also estimated, ppm: PVC-100; adipate plasticizer-70; tribasic lead sulfate-2 (load $49 \mathrm{~N})$.

Table 5 shows the color of the granules of the polyvinyl chloride composition at the exit from the IIRT-AM device. 
Table 5. Test results.

\begin{tabular}{cccccc}
\hline \multirow{2}{*}{$\begin{array}{c}\text { Plasticizer } \\
\text { Composition }\end{array}$} & $\mathbf{1 7 0}{ }^{\circ} \mathbf{C}$ & $\mathbf{1 7 5}{ }^{\circ} \mathbf{C}$ & $\mathbf{1 8 0}{ }^{\circ} \mathbf{C}$ & $\mathbf{1 8 5}{ }^{\circ} \mathbf{C}$ & $\mathbf{1 9 0}{ }^{\circ} \mathbf{C}$ \\
\cline { 2 - 6 } & White & White & White & White & White \\
\hline DOA & White & White & White & White & Yellow \\
\hline I & White & White & White & Yellow & Yellow \\
\hline II &
\end{tabular}

Comparison of the rheological properties of PVC compositions based on butyl butoxyethyl adipate (I) and decyl butoxyethyl adipate (II) (content $70 \mathrm{ppm}$ ) with similar compounds containing the industrial adipate plasticizer dioctyl adipate (DOA) showed that their fluidity in the temperature range $170-190{ }^{\circ} \mathrm{C}$ differs not so significantly (Figure 12).

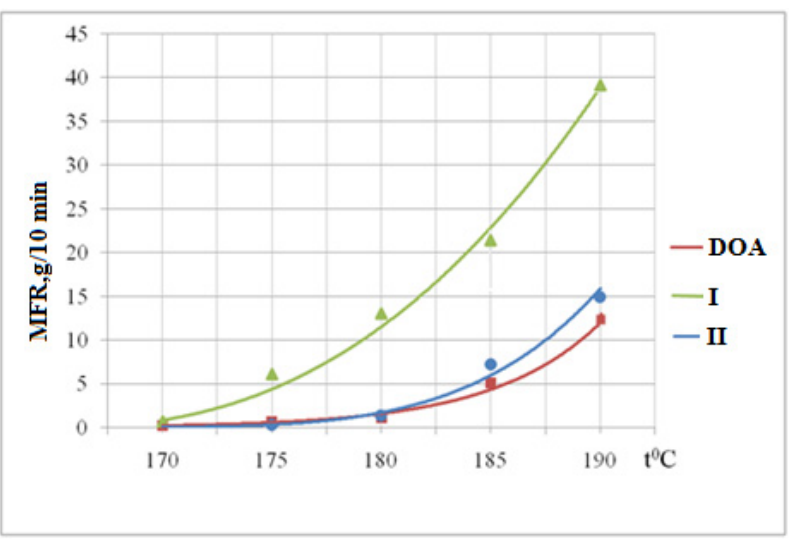

Figure 12. Dependence of the MFR of the PVC composition on temperature. I-II-Symbols of plasticizers (Table 1).

It has been experimentally established that, for composites based on PVC, with the same MFR values but containing different amounts of plasticizer, temperature and plasticizer content are linked by a linear relationship (Figure 13). The correlation coefficient for all considered samples is 0.99 .

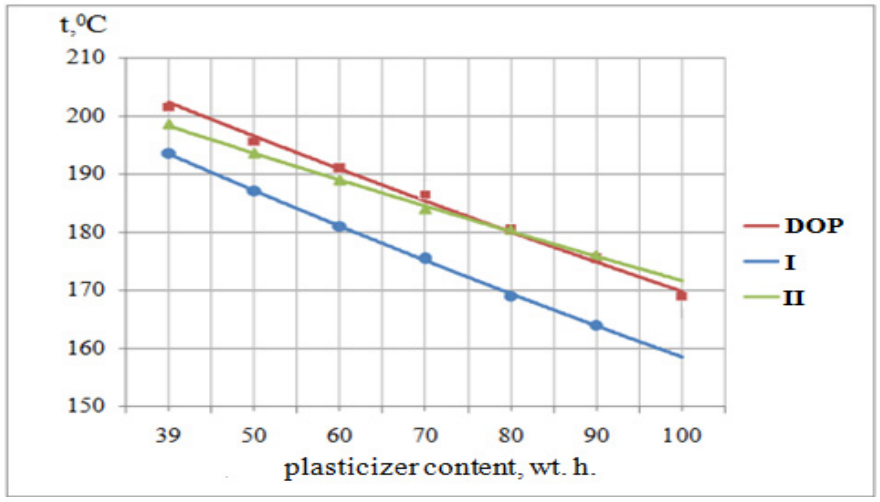

Figure 13. Dependence of the flow temperature of the PVC composition on the content of the plasticizer at constant MFR $=5 \mathrm{~g} / 10 \mathrm{~min}(\mathrm{r}=0.99)$. I-II-Symbols of plasticizers (Table 1).

A quantitative estimate of the effect of the plasticizer on the MFR of the polymer is the efficiency indicator $\theta$, which is numerically equal to the tangent of the slope of the obtained experimental straight lines to the abscissa axis and which shows the change in this temperature when 1 wt.h. of the plasticizer is introduced into the composition of the plastic. 


\section{Conclusions}

Thus, the synthesized derivatives of adipic acid butyl butoxyethyl adipate and decyl butoxyethyl adipate have a pronounced plasticizing effect with respect to PVC, which consists in a significant increase in the melt flow rate of PVC compounds. The melt flow rate of PVC compounds based on butyl butoxyethyl adipate and decyl butoxyethyl adipate products is even slightly higher than that of compositions of a similar composition containing industrial plasticizers DOP and DOA. The thermal stability of compositions containing the developed plasticizers, even with a small introduction of them into the recipe, is somewhat higher than the thermal stability of compositions based on DOP.

\section{Patents}

Patent 2716691 RU, Int. Cl. ${ }^{51}$ C08L 27/00 (2006.01). Plasticiser for compositions based on polyvinyl chloride. Mazitova A.K., Aminova G.K., Vikhareva I.N., Sukhareva I.A., Zaripov I.I., Akhmetov I.R. Proprietor Federalnoe gosudarstvennoe byudzhetnoe obrazovatelnoe uchrezhdenie vysshego obrazovaniya "Ufimskij gosudarstvennyj neftyanoj tekhnicheskij universitet" (RU).—№ 2019131313; Date of filing 2 October 2019; Date of publication 13 March 2020.

Author Contributions: Conceptualization, A.K.M.; methodology, G.K.A.; formal analysis, I.N.V.; investigation, I.N.V.; writing—original draft preparation, I.N.V.; writing—review and editing, A.K.M.; supervision, G.K.A. All authors have read and agreed to the published version of the manuscript.

Funding: This research received no external funding.

Institutional Review Board Statement: Not applicable.

Informed Consent Statement: Not applicable.

Data Availability Statement: The data presented in this study are available on request from the corresponding authors.

Conflicts of Interest: The authors declare no conflict of interest.

\section{References}

1. Statista. Available online: https://www.statista.com/statistics/282732/global-production-of-plastics-since-1950/ (accessed on 30 August 2020).

2. Fadina, Y.I. Analysis of the Russian polymer market and further ways of its development. Bus. Educ. Knowl. Econ. 2017, 1, 99-101.

3. Chamas, A.; Moon, H.; Zheng, J.; Qiu, Y.; Tabassum, T.; Jang, J.H.; Abu-Omar, M.; Scott, S.L.; Suh, S. Degradation Rates of Plastics in the Environment. ACS Sustain. Chem. Eng. 2020, 8, 3494-3511. [CrossRef]

4. Pospıšil, J.; Horák, Z.; Kruliš, Z.; Nešpůrek, S.; Kuroda, S. Degradation and aging of polymer blends. Thermomechanical and thermal degradation. Polym. Degrad. Stab. 1999, 65, 405-414. [CrossRef]

5. Ulyanov, V.M.; Rybkin, E.P.; Gudkovich, A.D.; Pishin, G.A. Polyvinyl Chloride; Chemistry: Moscow, Russia, 2000; p. 288.

6. Chodak, I. Degradable Polymers; Kluwer Academic Publishers: Dordrecht, The Netherlands, 2002.

7. Erceg, M.; Kovacic, T.; Klaric, I. Thermal degradation of poly(3-hydroxybutyrate) plasticized with acetyl tributyl citrate. Polym. Degrad. Stab. 2005, 90, 313-318. [CrossRef]

8. Pakharenko, V.A.; Pakharenko, V.V.; Yakovleva, R.A. Plastics in construction; Scientific Fundamentals and Technologies: St. Petersburg, Russia, 2010; p. 349.

9. Schiller, M. Additives to PVC. In PVC Additives. Performance, Chemistry, Developments, and Sustainability; Translated from English by Tikhonov, N.N.; Profession: Moscow, Russia, 2017; p. 400.

10. Grossman, R.F. Handbook of Vinyl Formulating, 2nd ed.; Grossman, F., Ed.; Translated from English by Guzeev, V.V.; Scientific Foundations and Technologies: St. Petersburg, Russia, 2009; p. 608.

11. Wypych, G. Handbook of Plasticizers; ChemTec Publishin: Scarborough, ON, Canada, 2004; p. 687.

12. Siracusa, V.; Rocculi, P.; Romani, S.; Dalla Rosa, M. Biodegradable polymers for food packaging: A review. Trends Food Sci. Technol. 2008, 19, 634-643. [CrossRef]

13. Hsissou, R.; Seghiri, R.; Benzekri, Z.; Hilali, M.; Rafik, M.; Elharfi, A. Polymer composite materials: A comprehensive review. Compos. Struct. 2021, 262, 113640. [CrossRef]

14. Stipek, J.; Daoust, H. Additives for Plastics; Springer Science \& Business Media: Berlin/Heidelberg, Germany, 2012; p. 243.

15. Lakeev, S.N.; Maydanova, I.O.; Mullakhmetov, R.F. Ester plasticizers for polyvinyl chloride. Russ. J. Appl. Chem. 2016, 89, 1-15. [CrossRef] 
16. Mekonnen, T.; Mussone, P.; Khalil, H.; Bressler, D. Progress in bio-based plastics and plasticizing modifications. J. Mater. Chem. A 2013, 1, 13379-13398. [CrossRef]

17. Staples, C.A.; Peterson, D.R.; Parkerton, T.F.; Adams, W.J. The environmental fate of phthalate esters: A literature review. Chemosphere 1997, 35, 667. [CrossRef]

18. Fromme, H.; Kücher, T.; Otto, T.; Pilz, K.; Müller, J.; Wenzel, A. Occurrence of phthalates and bisphenol A and F in the environment. Water Res. 2002, 36, 1429. [CrossRef]

19. Fernandez, M.P.; Ikonomou, M.G.; Buchanan, I. An assessment of estrogenic organic contaminants in Canadian wastewaters. Sci. Total Environ. 2007, 373, 250. [CrossRef] [PubMed]

20. Zeng, F.; Cui, K.; Xie, Z.; Wu, L.; Luo, D.; Chen, L.; Lin, Y.; Liu, M.; Sun, G. Distribution of phthalate esters in urban soils of subtropical city. J. Hazard. Mater. 2009, 164, 1171. [CrossRef]

21. Felder, J.D.; Adams, W.J.; Saege, V.W. Assessment of the safety of dioctyl adipate in freshwater environments. Environ. Toxicol. Chem. 1986, 5, 777-784. [CrossRef]

22. Gu, J.D. Biodegradability of plastics: The issues, recent advances, and future perspectives. Environ. Sci. Pollut. Res. 2021, 28, 1278-1282. [CrossRef] [PubMed]

23. Rakhimov, M.A.; Rakhimova, G.M.; Imanov, E.M. Problems of utilization of polymer waste. Fundam. Res. 2014, 8, 331-332.

24. Gogol, E.V.; Mingazetdinov, I.K.; Gumerova, G.I. Analysis of existing methods of utilization and processing of polymer waste. Bull. Kazan Technol. Univ. 2013, 10, 163-167.

25. Gu, G.D. Microbiological deterioration and degradation of synthetic polymeric materials: Recent research advances. Int. Biodeterior. Biodegrad. 2003, 53, 69-91. [CrossRef]

26. Shah, A.A.; Hasan, F.; Hameed, A.; Ahmed, S. Biological degradation of plastics: A comprehensive review. Biotechnol. Adv. 2008, 26, 246-265. [CrossRef]

27. Janeschitz-Kriegl, H. Polymer Melt Rheology and Flow Birefringence; Springer Science \& Business Media: Berlin/Heidelberg, Germany, 2012; p. 524.

28. Aydin, I. Evaluation of Rheological Properties during Extrusion Compounding of Soft PVC Powder Blends. Int. J. Emerg. Technol. Adv. Eng. 2016, 6, 210-214.

29. Han, C.D. Rheology in Polymer Processing; Vinogradov, G.V., Fridman, M.L., Eds.; Chemistry: Moscow, Russia, $1979 ;$; p. 368.

30. Yershov, S.V. Investigation of rheological properties of electrical insulating polymers. Bull. PNRPU 2012, 2, 88-98.

31. Yankov, V.I. Non-isothermal flow of polymer liquids in screw seals with longitudinal circulation. Chem. Oil Gas Eng. 2006, 3, $12-15$.

32. Mazitova, A.K.; Vikhareva, I.N.; Aminova, G.K.; Savicheva, J.N. Application of Zinc Oxide to Obtain and Modify Properties of Adipate Plasticizer of Polyvinyl Chloride. Polymers 2020, 12, 1728. [CrossRef]

33. Vikhareva, I.N.; Aminova, G.K.; Moguchev, A.I.; Mazitova, A.K. The effect of a zinc-containing additive on the properties of PVC compounds. Adv. Polym. Technol. 2021, 2021, 5593184. [CrossRef]

34. Mazitova, A.K.; Vikhareva, I.N.; Aminova, G.K. Designing of green plasticizers and assessment of the effectiveness of their use. Polymers 2021, 13, 1761. [CrossRef]

35. Interstate Standard 8728-88. Plasticizers Specifications; IPK Publishing House of Standards: Moscow, Russia, 2003 ; p. 11.

36. Interstate Standard 18329-2014. Liquid Resins and Plasticizers, Methods for Determination of Density; FSA Standartinform: Moscow, Russia, 2015; p. 8.

37. Interstate Standard 11645-73. Plastics Method for Determining the Melt Flow Index of Thermoplastics (with Changes N 1, 2, 3) M.; Publishing House of Standards: Moscow, Russia, 1994. 